\author{
Jurnal Pemberdayaan: Publikasi Hasil Pengabdian kepada Masyarakat \\ Vol. 2, No. 2, Agustus 2018, Hal. 249-256 \\ ISSN: 2088 4559; e-ISSN: XXXX-XXXX \\ DOI:
}

\title{
PELATIHAN PERAN SERTA KADER POSYANDU DALAM PEMBERIAN EDUKASI KEPADA MASYARAKAT
}

\author{
Nina Salamah ${ }^{1}$, Nanik Sulistyani ${ }^{2}$ \\ Fakultas Farmasi Universitas Ahmad Dahlan Yogyakarta ${ }^{1,2}$ \\ Email: ninasalamah1996@gmail.com
}

\begin{abstract}
ABSTRAK
Posyandu merupakan wadah yang dapat digunakan untuk upaya pencegahan dan penanggulangan masalah kesehatan baik gizi, kesehatan ibu dan anak, Pola hidup bersih sehat, imunisasi dan sebagainya. Lewat model penimbangan dan pemantauan gizi tiap bulan juga dapat dijadikan sebagai alat surveilans gizi yang tujuan akhirnya adalah upaya pencegahan dan penanggulangan masalah gizi balita. Jika pelaksanaan posyandu baik maka target program akan terpenuhi, akan tetapi jika pelaksanaan posyandu kurang lancar maka target tidak akan dapat terpenuhi. Dalam praktek di masyarakat pelaksanaan Posyandu masih mengalami beberapa kendala antara lain kemampuan kader yang masih kurang dalam kegiatan penyuluhan kesehatan kepada masyarakat. Tujuan pengabdian ini yaitu untuk meningkatkan kemampuan kader posyandu dalam pengukuran dan penimbangan balita serta status gizi ibu dan balita. Perlu juga peningkatan kemampuan penyuluhan kader, mengingat keterbatasan tenaga penyuluh di puskesmas Depok 3. Hal ini berimplikasi pada penanganan permasalahan kesehatan ibu dan balita lebih cepat. Metode yang digunakan dalam pelatihan ini yaitu dengan pemberian kegiatan pelatihanpelatihan untuk peningkatan skill kader posyandu disertai dengan mengadakan lomba penyuluhan kepada masyarakat dan pemberian hadiah berupa uang pembinaan untuk melengkapi sarana pra sarana yang menunjang kegiatan posyandu. Melalui kegiatan ini diharapkan peran posyandu sebagai ujung tombak pemantauan status gizi di masyarakat dapat lebih optimal. Hasil dari kegiatan ini adalah meningkatkan kemampuan kader dalam memberikan penyuluhan kepada masyarakat dengan metode yang lebih menarik sehingga meningkatkan kepercayaan diri kader untuk bisa berbagi kepada masyarakat tentang kesehatan. Pelatihan ini meluas karena juga diberikan kepada kader posyandu lansia dan juga posbindu.
\end{abstract}

Kata Kunci : posyandu, kader, penyuluhan, posbindu

\begin{abstract}
Posyandu is a place that can be used as an effort to prevent and overcome health problems, such as nutrition, maternal and child health, a healthy lifestyle, immunization and so on. Through a model of weighing and monitoring nutrition every month, it can also be used as a nutrition surveillance tool whose ultimate goal is efforts to prevent and control under-fives nutrition problems. If the implementation of the Posyandu is good, the target of the program will be fulfilled, but if the implementation of the posyandu is not smooth then the target will not be fulfilled. In practice in the community the implementation of Posyandu still faces several obstacles, among others, the ability of cadres who are still lacking in health education activities to the community. The purpose of this service is to improve the ability of Posyandu cadres in measuring and weighing infants and nutritional status of mothers and toddlers. It is also necessary to increase cadre counseling capacity, given the limited extension staff in Depok 3 health centers. This has implications for handling maternal and toddler health problems more quickly. The method used in this training is by providing training activities to improve Posyandu cadre skills accompanied by conducting counseling competitions to the community and giving prizes in the form of training to complete the pre-facilities to support the activities of the Posyandu. Through this activity, it is expected that Posyandu's role as the spearhead of monitoring nutritional status in the community can be optimized. The results of this activity increased the cadre's ability to provide counseling to the community with more interesting methods
\end{abstract}


so as to increase the self-confidence of cadres to be able to share with the community about health. This training was extensive because it was also given to Posyandu cadres in the elderly and also Posbindu.

Key word : posyandu, cadre, counseling, posbindu

\section{PENDAHULUAN}

Dukuh Nologaten dan Dukuh Seturan merupakan bagian dari Wilayah Desa Caturtunggal, Kecamatan Depok, Kabupaten Sleman. Desa Caturtunggal terdiri dari 20 padukuhan, dua diantaranya adalah Padukuhan Nologaten dan Padukuhan Seturan. Secara sosiokultural, kedua wilayah tersebut sangat heterogen, namun suasana gotong-royong masih lekat di antara warga. Setiap RT dan RW di wilayah tersebut selalu mengadakan pertemuan rutin bulanan untuk membahas segala sesuatu yang terjadi dan dikembangkan di wilayah masing-masing. Posyandu menjadi salah satu program rutin yang dilaksanakan di Nologaten dan Seturan. Jumlah pengurus kader per dukuh sekitar 10 orang ditambah dengan 2 kader tiap RT sehingga total jumlah kader per dukuh sekitar 13-16 orang. Jumlah penduduk miskin di kedua Dukuh tersebut cukup banyak, sehingga keberadaan posyandu sangat membantu mereka dalam pemantauan kesehatan balita. Sayangnya fasilitas peralatan posyandu masih minimal dan proses pencataan hasil pemantauan kesehatan masih sangat manual (gambar 1) sehingga pihak puskesmas tidak cepat mengakses dan memberikan respon bila ada masalah kesehatan terhadap ibu dan balita. Disamping itu tingkat pendidikan kader tidak ada yang memiliki latar belakang pendidikan kesehatan. Oleh karena itu dalam pelaksanaan program kegiatan posyandu masih sangat perlu untuk pembinaan. Hal ini sangat kontras dengan padukuhan lain di Caturtunggal antara lain Padukuhan Karangmalang yang sudah jauh lebih maju dalam penyelenggaraan sistem di padukuhan termasuk kegiatan posyandunya.

Pelaksanaan posyandu juga masih mengalami beberapa kendala antara lain kemampuan kader yang masih kurang dalam kegiatan penimbangan dan pengukuran tinggi badan balita, kemampuan kader yang kurang dalam menginterpretasikan hasil pengukuran status gizi dan peran masyarakat yang kurang sehingga berimbas pada cakupan balita yang ditimbang kurang dari target yang ditetapkan. Saat ini masih dijumpai posyandu yang mempunyai cakupan balita yang ditimbang (D/S) kurang dari 80\% (Puskesmas Depok 3, 2014). Berdasarkan laporan surveilans gizi Puskesmas Depok 3, cakupan D/S pada puskesmas tersebut kurang dari target program. Tahun 2012 cakupan D/S 75,65 \% dan tahun 2013 menurun menjadi 74,45 \%. Baru di tahun 2014 meningkat menjadi 77,48 \% (Dinkes Sleman, 2012). Walaupun sudah ada peningkatan yang cukup signifikan akan tetapi capaian tersebut tidak merata di seluruh 
wilayah. Salah satu posyandu yang belum memenuhi target yaitu posyandu di Nologaten dan Seturan.

Prioritas masalah yang disepakati akan diselesaikan yaitu meningkatnya cakupan penimbangan balita D/S serta meningkatnya kemampuan kader dalam teknik serta metode dalam memberikan penyuluhan kesehatan kepada masyarakat.

\section{METODE}

Metode pendekatan yang akan dipakai untuk menyelesaikan persoalan mitra yaitu dengan memberikan rangkaian kegiatan pelatihan untuk pengelolaan posyandu dan pelatihan memberikan penyuluhan kesehatan kepada masyarakat. Praktek kemampuan penyuluhan kader ini juga akan dilombakan untuk mengetahui kemampuan kader dari hasil pelatihan.

Beberapa prosedur kerja yang akan dilaksanakan dalam kegiatan pengabdian masyarakat (PM) yaitu :

a. Pelatihan tentang tugas dan fungsi kader posyandu dalam upaya optimalisasi pelaksanaan kegiatan posyandu (Sandjaja, 2009). Tujuan kegiatan ini adalah untuk memberikan bekal pengetahuan kader tentang tugas dan fungsi kader dalam posyandu. Sasaran kegiatan yaitu kader posyandu Nologaten dan Seturan

b. Pelatihan tentang cara memotivasi masyarakat dengan kunjungan ke rumah-rumah. Tujuan pelatihan ini yaitu untuk memberikan tehnik pada kader dalam upaya pendekatan sasaran posyandu dengan kunjungan ke rumah-rumah warga. Sasaran kegiatan yaitu semua kader.

c. Pelatihan tentang cara pemberian penyuluhan di masyarakat Tujuan kegiatan adalah memberikan bekal kepada kader tentang cara memberikan penyuluhan yang efektif di masyarakat. Kader sebagai perpanjangan tangan puskesmas dalam penyampaian masalah kesehatan di masyarakat mempunyai kewajiban untuk memberikan penyuluhan yang berguna untuk masyarakat.

Berdasarkan permasalahan yang ada pada posyandu di kedua mitra maka diperlukan beberapa kepakaran untuk bisa menyelesaikan prioritas masalah yang akan dilaksanakan yaitu upaya untuk revitalisasi posyandu untuk meningkatkan skill kader dan upaya peningkatan cakupan penimbangan balita D/S dengan meningkatkan peran posyandu sebagai ujung tombak data surveilans gizi. Kepakaran yang dibutuhkan adalah:

1. Komunikasi, Informasi dan Edukasi oleh kader

2. Metode penyuluhan yang efektif 
3. Pengelolaan posyandu

4. Gizi ibu dan anak

5. Kesehatan masyarakat

\section{HASIL, PEMBAHASAN, DAN DAMPAK}

Program pengabdian masyarakat dengan bantuan pendanaan dari LPPM UAD dengan tema: PELATIHAN PERAN SERTA KADER POSYANDU DALAM PEMBERIAN EDUKASI KEPADA MASYARAKAT, bekerjasama dengan posyandu wilayah Nologaten dan Seturan Yogyakarta. Acara inti pelatihan ini dilaksanakan pada hari Sabtu dan Ahad, 5-6 Januari 2019. Metode yang digunakan dalam pengabdian masyarakat ini yaitu dengan pemberian kegiatan pelatihan-pelatihan untuk peningkatan skill kader posyandu disertai dengan mengadakan lomba penyuluhan efektif kepada masyarakat yang diikuti oleh 5 kelompok posyandu, yang terdiri dari posyandu balita, posyandu lansia dan posbindu dari kedua wilayah tersebut. Pemenang kegiatan lomba posyandu ini diberikan hadiah berupa uang pembinaan untuk melengkapi sarana pra sarana yang menunjang kegiatan posyandu masing masing. Melalui kegiatan ini diharapkan peran posyandu sebagai ujung tombak pemantauan kesehatan di masyarakat dapat lebih optimal.

Hasil dari kegiatan ini meningkatkan kemampuan kader dalam memberikan penyuluhan kepada masyarakat dengan metode yang lebih menarik sehingga meningkatkan kepercayaan diri kader untuk bisa berbagi kepada masyarakat tentang kesehatan. Pelatihan ini meluas tidak hanya untuk kader posyandu balita tapi juga diberikan kepada kader posyandu lansia dan juga posbindu. Peran serta aparat pemerintahan juga sangat besar dalam mendukung kegiatan ini, sehingga kegiatan ini di buka langsung oleh kepala dukuh Nologaten dan diikuti dari awal sampe akhir oleh ibu dukuh Nologaten maupun Seturan. Salah satu foto kegiatan diawali dengan sambutan dari kepala dusun Nologaten dapat dilihat pada gambar 1. Hal ini menunjukkan dukungan aparat padukuhan terhadap kegiatan ini. 


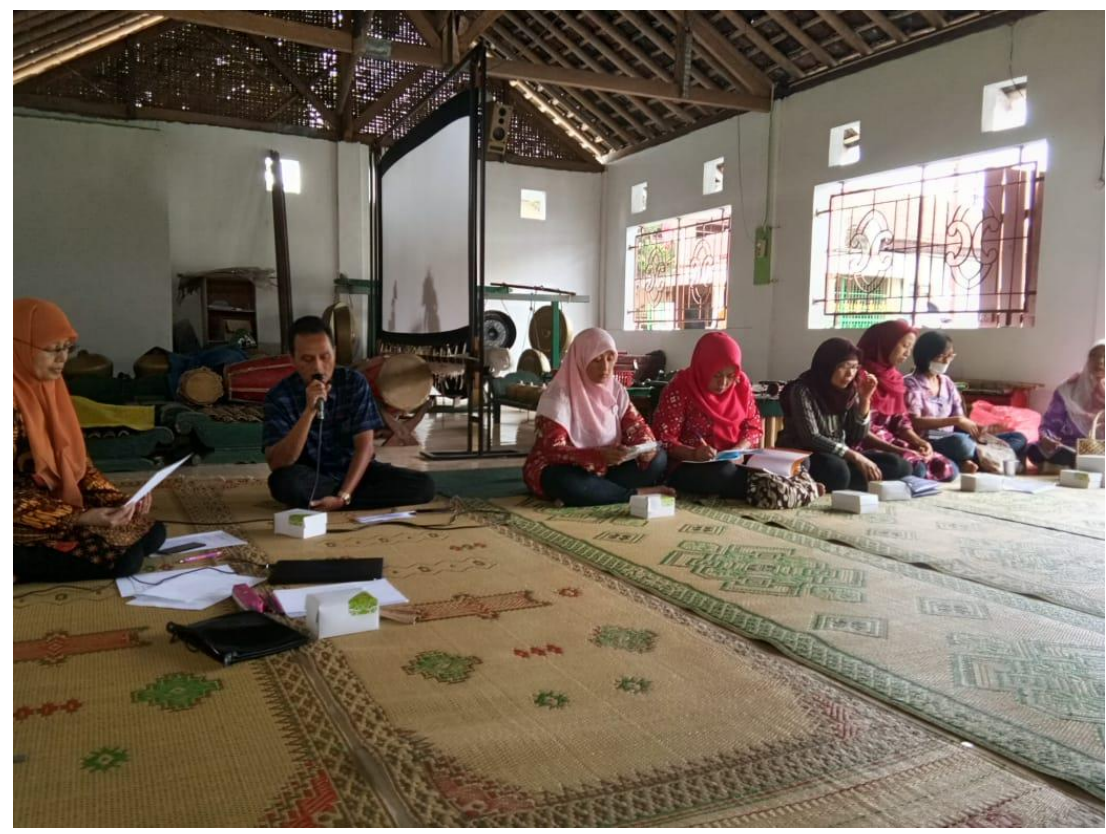

Gambar 1. Foto kegiatan dawali sambutan kepala dukuh Nologaten

\section{Analisis Kader Peserta Pelatihan}

Berdasarkan hasil koordinasi dengan dukuh Nologaten dan Dukuh Seturan disepakati bahwa peserta pelatihan bukan hanya kader yang berasal dari posyandu balita saja tapi juga kader dari posyandu lansia dan posbindu. Demikian juga permintaan dari dukuh Seturan, yang juga melibatkan posyandu lansia dan balita dari Seturan. Berdasarkan gambar 2 dapat dilihat komposisi kader peserta pelatihan. Ternyata antusiasme kader lansia lebih banyak dari pada kader balita maupun kader posbindu. Peserta dari kader posbindu, jumlahnya lebih sedikit karena peserta hanya berasal dari Nologaten, sedangkan posbindu Seturan belum terbentuk.

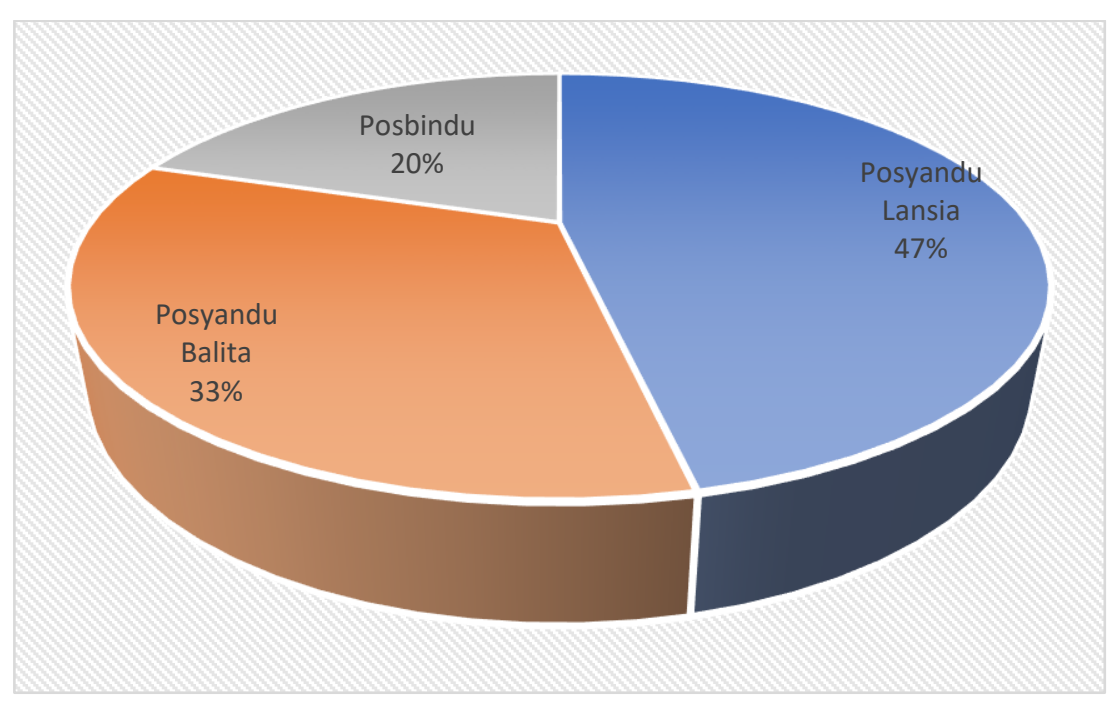

Gambar 2. Komposisi peserta pelatihan kader posyandu 


\section{Analisis berdasarkan tingkat Pendidikan Kader}

Data tingkat pendidikan peserta bisa dilihat pada gambar 3, dimana kader lulusan SMA mendominasi. Hal ini sesuai dengan arahan puskesmas bahwa kader diusahakan minimal lulusan SLTA, agar transfer ilmu kepada kader lebih mudah. Tapi usia kader yang aktif bervariasi baik di Nologaten maupun Seturan. Di Nologaten usia kader termuda 30 tahun dan usia kader tertua 60 tahun, sedangkan di Seturan usia kader termuda 35 tahun dan usia tertua 58 tahun.

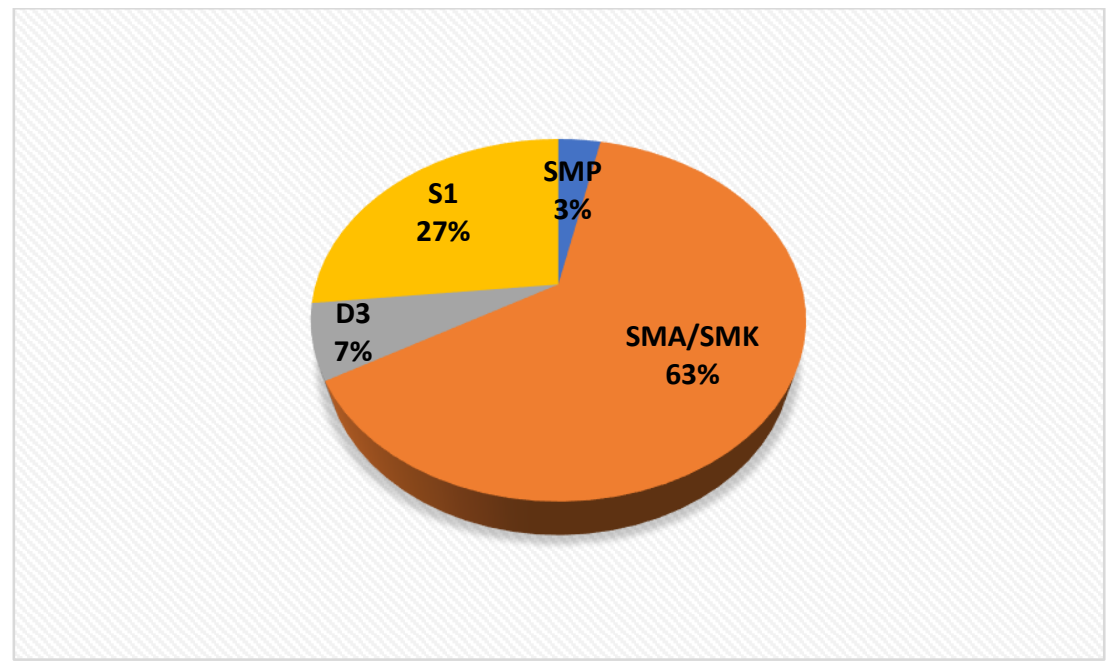

Gambar 3. Tingkat pendidikan kader di Nologaten dan Seturan

\section{Kegiatan yang Terlaksana}

Berdasarkan hasil evaluasi keberhasilan pelatihan dalam hal pengetahuan, terlihat bahwa terjadi peningkatan pengetahuan peserta antara sebelum dan sesudah pelatihan. Hal ini bisa dilihat pada gambar 4 .

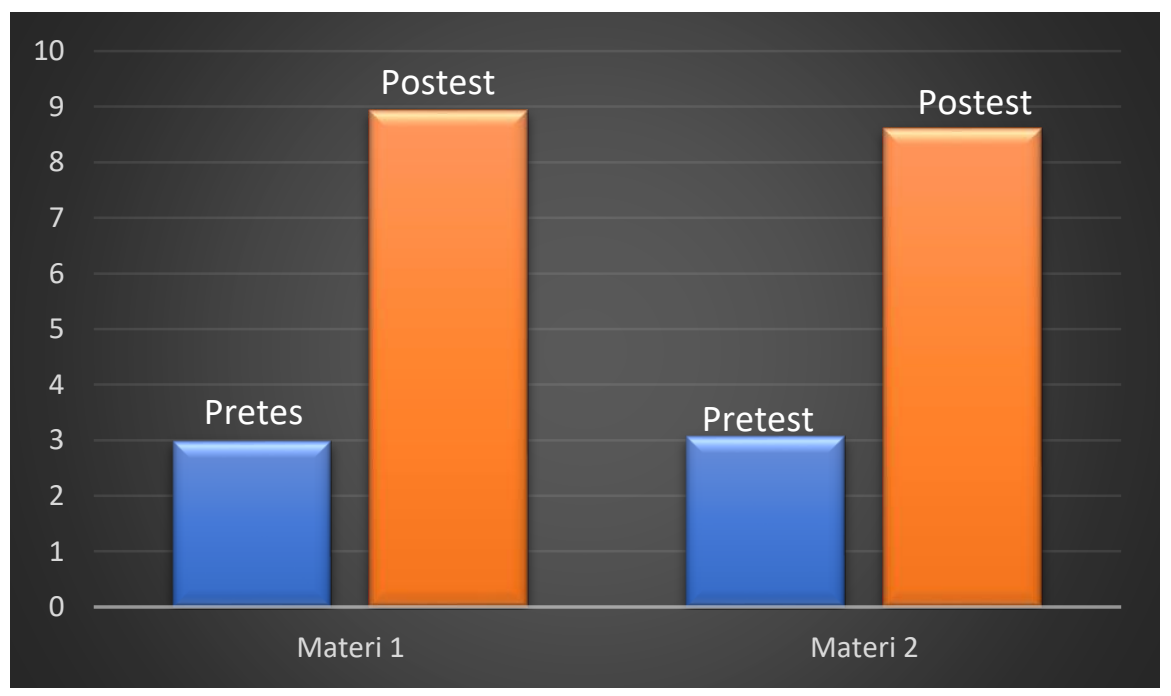

Gambar 4. Perbandingan tingkat keberhasilan program berdasarkan tingkat pengetahuan peserta antara sebelum dan sesudah dan pelatihan 
Berdasarkan hasil pelatihan, kepercayaan diri kader meningkat dalam upaya memberikan penyuluhan kepada masyarakat. Hal ini bisa dilihat dari hasil lomba yang diikuti oleh 5 kelompok peserta dimana tiap peserta terdiri dari 4 orang, dengan waktu lomba penyuluhan tiap kelompok sekitar 15 menit. Tahapan penyuluhan mulai dari salam pembuka hingga salam penutup dan juga pemberian ice breaking agar audience penyuluhan tidak bosan juga dilakukan oleh peserta lomba dengan sangat baik dan percaya diri. Salah satu gambaran ice breaking dari peserta lomba bisa dilihat pada gambar 5 .

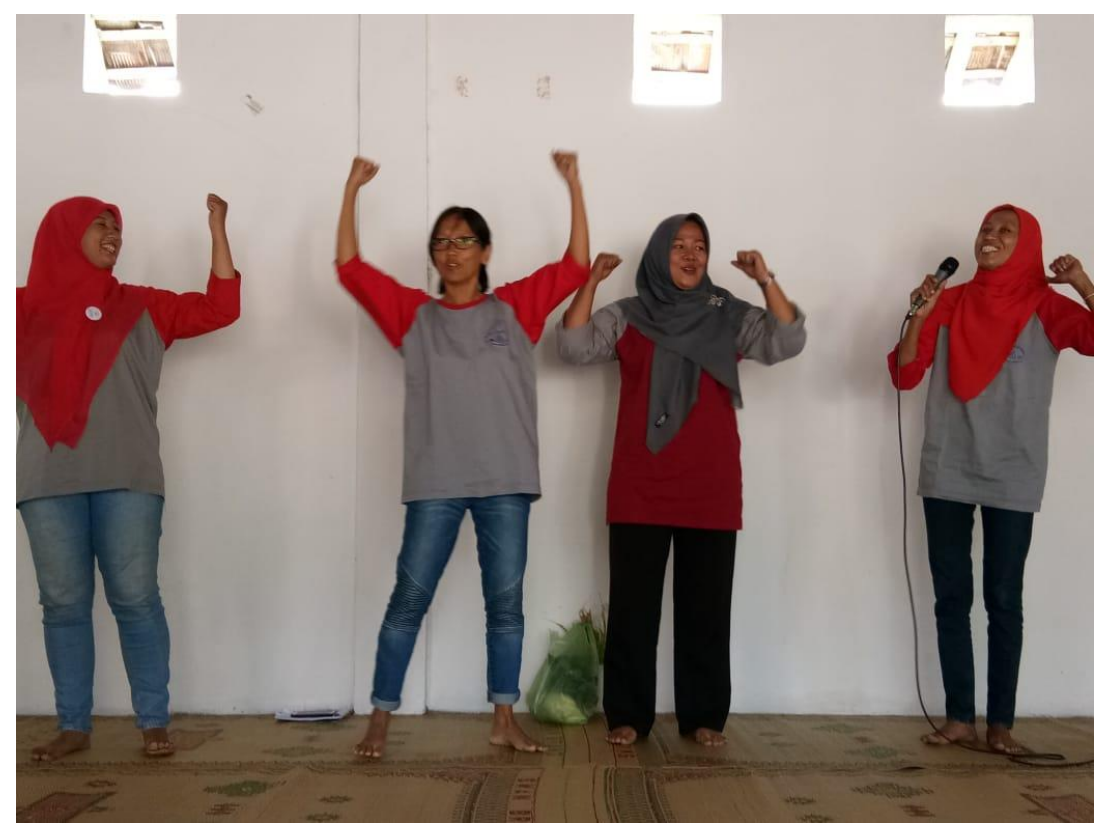

Gambar 5. Foto lomba penyuluhan pada saat ice breaking

\section{SIMPULAN}

Agenda pengabdian masyarakat dengan peserta kader posyandu balita, posyandu lansia dan posbindu terlaksana dengan baik. Tingkat keberhasilan pelatihan posyandu terlihat dari peningkatan pengetahuan yang signifikan antara sebelum dan setelah pelatihan.

\section{DAFTAR PUSTAKA}

Dinas Kesehatan Sleman, 2012, Laporan Penilaian Status Gizi Balita Kabupaten Sleman.

Puskesmas Depok 3, 2014, Laporan Penilaian Status Gizi Balita Wilayah Puskesmas Depok 3.

Sandjaja, 2009, Kamus Gizi. Jakarta: PT Kompas Media Nusantara. 


\section{UCAPAN TERIMAKASIH}

Terima kasih kepada LPPM UAD atas bantuan dana yang diberikan sehingga kegiatan ini terlaksana. 